\title{
Dye Sensitized Solar Cells with Ito Films Prepared By the Acrylamide Sol Gel Route
}

\author{
G.Ramanathan ${ }^{1}$,R.John Xavier $^{2}$,K.R.Murali ${ }^{3}$ \\ 1. Department of physics, Sri Sairam Engineering College, Chennai, India. \\ 2. Department of Physics, Periyar E.V.R College, Trichy, India. \\ 3. ECMS Division, CSIR-CECRI, Karaikudi, India
}

\begin{abstract}
Tin doped Indium oxide films were prepared by the acrylamide Sol gel dip coating method. The films were post heat treated in air at different temperatures in the range $350-450^{\circ} \mathrm{C}$. The films exhibited cubic structure. The films showed $85 \%$ transmission and exhibited a resistivity of $1.0 \times 10^{-4} \mathrm{Ohm} \mathrm{cm}$. Dye sensitized solar cells fabricated with the ITO electrodes/dyelelectrolyte/ tin oxide configuration yielded efficiency in the range of $1.59-2.20 \%$ at $100 \mathrm{~mW} \mathrm{\textrm {cm } ^ { - 2 }}$ illumination.
\end{abstract}

Keywords- Acrylamide route, ITO, Semiconductor, Thin films

\section{Introduction}

Transparent conducting oxide (TCO) films have been widely used for a variety of optoelectronic devices, energy efficient windows, light emitting diode (LEDs), flat panel displays (FPD), storage-type cathode ray tubes, solar cells, gas sensors, photo catalysts, and surface layers in electroluminescent applications. Among the existing TCOs, Sn doped $\operatorname{In}_{2} \mathrm{O}_{3}$ (ITO) is one of the most frequently used material because of its unique characteristics such as low resistivity, high optical transmittance over the visible wavelength region, excellent adhesion to substrates and chemical stability. ITO is an $\mathrm{n}$ type semiconductor with a band gap between 3.5 and $4.3 \mathrm{eV}$ at room temperature with bixbyte structure. Several techniques have been employed for the deposition of ITO thin films. In this work, the polyacrylamide gel route was employed for the deposition of ITO thin films.

\section{Experimental Method}

ITO thin films (10\% Sn doped Indium oxide) were deposited by the sol gel dip coating method adopting the following procedure. Clean glass substrates were used for the deposition of the films. $10 \mathrm{ml}$ of 0.45 $\mathrm{M}$ solution of Indium (III) chloride and $0.05 \mathrm{M} \mathrm{SnCl}_{4}$ were taken in a clean glass beaker. The solution was heated to $70^{\circ} \mathrm{C}$ and the $\mathrm{pH}$ was brought to 9 by the addition of ammonia, then $1 \mathrm{gm}$ of Acrylamide was added followed by the addition of $0.25 \mathrm{gm}$ of $\mathrm{N}, \mathrm{N}$, bis methylene acrylamide. After $20 \mathrm{~min}, 2 \mathrm{mg}$ ammonium persulphate initiator was added to this mixture. The solution became viscous. Cleaned micro glass slides $(2.5 \mathrm{~cm}$ $x 7.5 \mathrm{~cm}$ ) were immersed into the viscous solution and withdrawn at the rate of $1 \mathrm{~cm} \mathrm{~min}^{-1}$. The film formed on the surface was dried in an air oven for about 15 min followed by annealing in air at different temperatures in the range of $350-450^{\circ} \mathrm{C}$ for different durations in the range of $15 \mathrm{~min}$ to $90 \mathrm{~min}$. The optimized duration for heat treatment was $50 \mathrm{~min}$. The films were characterized for their structural, optical and electrical properties.

\section{Result And Discussion}

X-Ray Diffraction Patterns of ITO films as a function of the post heat treatment temperature are shown on Fig.3.1.The ITO thin films are polycrystalline and crystallize in a cubic structure of the bixbyite $\mathrm{Mn}_{2} \mathrm{O}_{3}$ (I) type structure, since (222) and (400) oriented peaks, characteristic of a cubic structure, are present on the diffractograms. The preferred growth orientation of ITO thin films depends on the post heat treatment temperature. The ratio (400) $I$ (222) increase with increasing temperature. Others peaks corresponding to (411); (622); (440) reflections are also observed, but their intensity is very small compared to that of the (400) peak. Nevertheless, their presence indicate that others orientations are possible on the films and that these orientations do not disappear with increasing temperature. The mean crystallite size $D$ was calculated from the (222) diffraction peaks using Debye-Scherer's formula:

$$
\mathbf{D}=\mathbf{K} \lambda / \boldsymbol{\beta} \cos \boldsymbol{\theta}
$$

in which $\lambda$ is the $\mathrm{X}$-ray wavelength $\left(1.548 \mathrm{~A}^{\circ}\right.$ for $\left.\mathrm{Cu}(\mathrm{K} \alpha)\right), K=180 / \pi, \theta$ is the diffraction angle and $\beta$ is the full line-width at half maximum of the (400) and (222) peaks. The line-widths were measured at a narrow slit width for better resolution. The mean size increases from $30 \mathrm{~nm}$ to $40 \mathrm{~nm}$ with increasing post heat treatment temperature. 


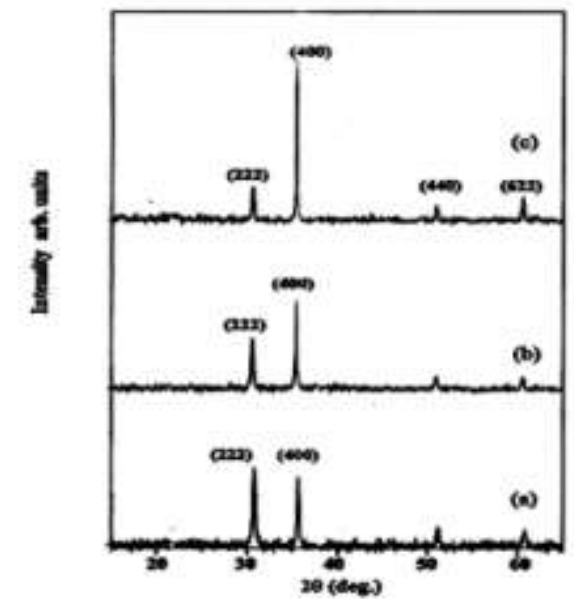

Fig. 3.1 - XRD patterns of Sn doped indium oxide films post heat treated in air at different temperatures $(a) 350^{\circ} \mathrm{C}\left(\right.$ b) $400^{\circ} \mathrm{C}$ (c) $450^{\circ} \mathrm{C}$

Fig.3.2 confirms qualitatively the presence of indium, tin and oxygen elements. This analysis shows that the atomic percentage are, In $(51.33 \%)$, Sn $(6.58 \%)$ and O (42.09\%).

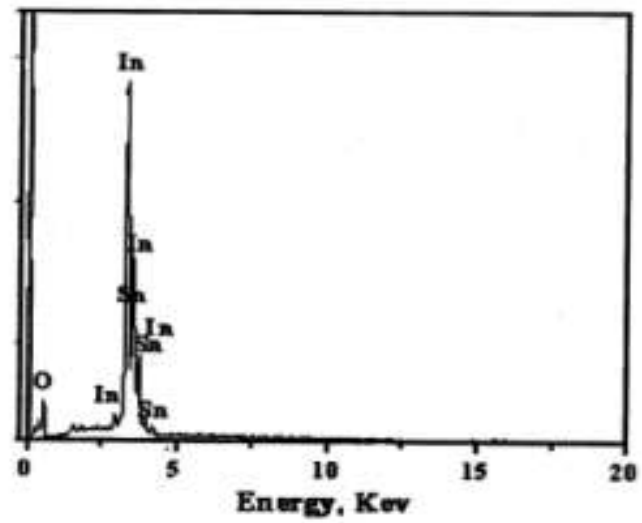

Fig. 3.2 - EDAX spectrum of ITO films post heat treated at $450^{\circ} \mathrm{C}$

XPS spectra for O 1s peak, In 3d and Sn 3d doublets are shown in Fig.3.3. These show the evidence of only one binding state for In and Sn since there is no sign of broadening or splitting of the peaks. The figures clearly indicate that oxygen is bonded to the indium and tin and that ITO is formed [1]. The binding energy of In $3 \mathrm{~d}_{5 / 2}$ at $445.1 \mathrm{eV}$ measured from ITO film shown in Fig.3.3 can be attributed to the $\operatorname{~In}^{3+}$ bonding state from $\mathrm{In}_{2} \mathrm{O}_{3}$ which corresponds to the previous studies [2]. The binding energy of $\mathrm{Sn} 3 \mathrm{~d}_{5 / 2}$ is at $487.1 \mathrm{eV}$ of the fig.3.3 and corresponds to the $\mathrm{Sn}^{4+}$ bonding state from $\mathrm{SnO}_{2}[2]$.
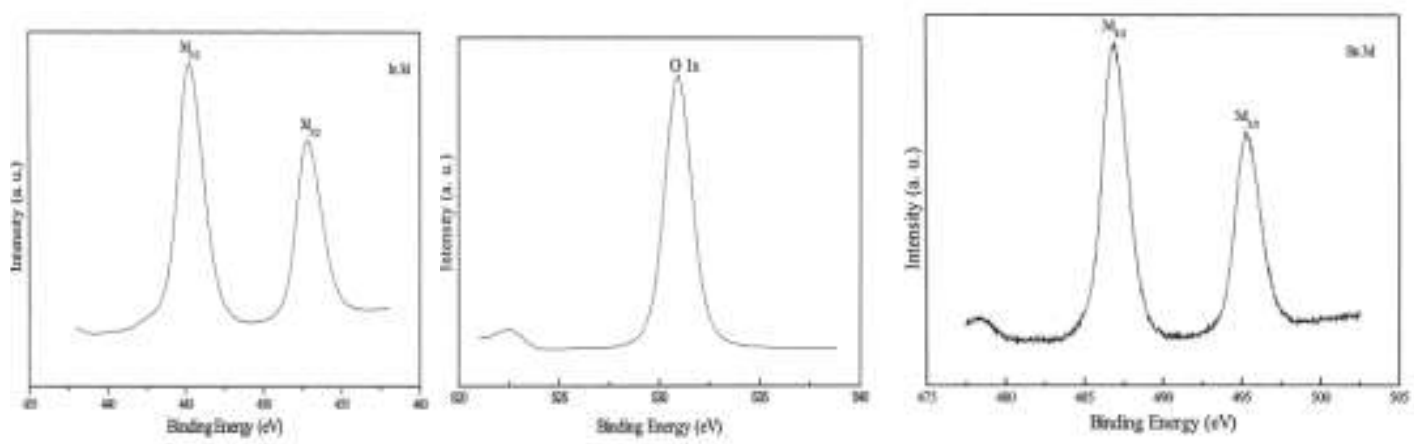

Fig. 3.3 - XPS spectra of $10 \%$ Sn doped indium oxide

Fig.3.4 Shows typical transmittance curves plotted as a function of wavelength for the films post heat treated at different temperatures. In addition to the high transmittance (visible range), high infrared reflectance was also obtained in the Sn-doped ITO films. A shift of the absorption edge to shorter wavelengths with changes in heat treatment temperature was also apparent and is related to the Burstien-Moss effect [3]. 


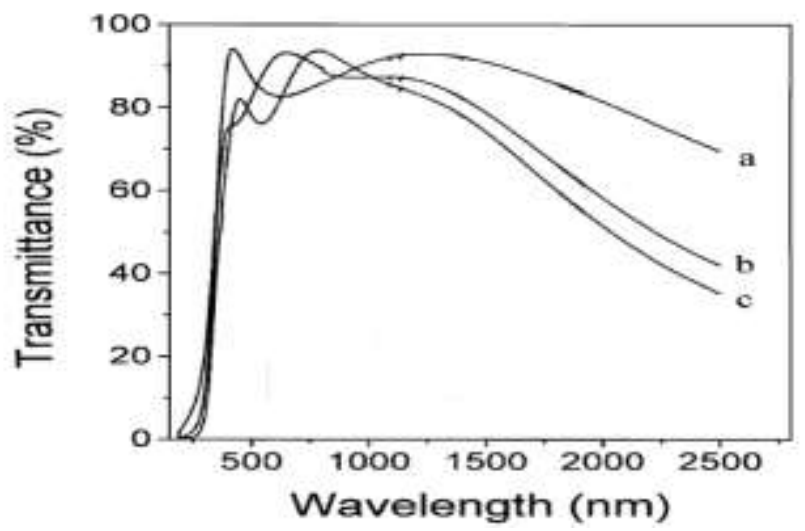

Fig. 3.4 - Transmission spectra of ITO films post heat treated at different temperatures (a) $450^{\circ} \mathrm{C}$ (b) $400^{\circ} \mathrm{C}$ (c) $350^{\circ} \mathrm{C}$

Transport parameters like mobility and carrier density were obtained from Hall measurements. Resistivity was obtained by the four probe resistivity method. The resistivity of the films varied from $10^{-4}$ to $10^{-3}$ $\mathrm{ohm} \mathrm{cm}$ as the post deposition temperature decreased. Mobility values varied from 25 to $15 \mathrm{~cm}^{2} \mathrm{~V}^{-1} \mathrm{~s}^{-1}$. The carrier density values decreased from $1.0 \times 10^{21} \mathrm{~cm}^{-3}$ to $1.0 \times 10^{20} \mathrm{~cm}^{-3}$ as the post heat treatment temperature decreased. The resistivity value is comparable with electron beam evaporated ITO films [4].

All the ITO films post heat treated at different temperatures were sensitized in a dye solution of cis-di (thiocyanate) bis (2, 2'-bipyridyl-4,4'-di-carboxylate) ruthenium (II) (R535, N3-dye, Solaronix) for $12 \mathrm{~h}$ at room temperature. Carbon paste coated on a FTO substrate was used as a counter electrode. The Dye sensitized solar cell (DSSC) was fabricated by clamping the dye-sensitized ITO photo electrode against carbon counterelectrode and filling the inter-electrode space by the electrolyte of $0.5 \mathrm{M} \mathrm{KI}, 0.05 \mathrm{M} \mathrm{I}_{2}$ and $0.05 \mathrm{M}$ 4-tertbutylpridine using capillary force. The active cell area was $0.25 \mathrm{~cm}^{2}$. The cell was irradiated with a $250 \mathrm{~W}$ Xenon lamp with ultraviolet and an infrared-blocking filter. The intensity of light was $100 \mathrm{~mW} \mathrm{~cm}{ }^{-2}$. The cell configuration was ITO/Dye/Electrolyte/FTO.

The important parameter of the DSSC is the photoelectric conversion efficiency. The photoelectric conversion efficiency of solar cells is the ratio of the output power to the incident power. The efficiency $(\eta)$ of the DSSCs can be calculated from the expression [5]

$$
\eta=\left(\mathbf{J}_{\text {SC }} V_{\text {oc }} F F\right) / \mathbf{P}_{\text {in }}
$$

Where $\mathrm{J}_{\mathrm{SC}}$ is the photocurrent, $\mathrm{V}_{\mathrm{OC}}$ is the open-circuit voltage, $\mathrm{FF}$ is the fill factor: $\mathrm{FF}=$ $(\mathrm{I} \times \mathrm{V})_{\max } / \mathrm{J}_{\mathrm{SC}} \mathrm{V}_{\mathrm{OC}}$, and the $\mathrm{P}_{\text {in }}$ is the intensity of the incident light. Fig. 3.5 shows the photocurrent-photo voltage characteristic curve of DSSCs using the ITO films heat treated at different temperatures. The $\eta, F F, V_{\mathrm{OC}}$, and $\mathrm{J}_{\mathrm{SC}}$ of the DSSCs are summarized in Table 3.1, from the figure it is observed that the DSSC with the ITO photo electrode heat treated at $450^{\circ} \mathrm{C}$, shows the maximum efficiency of $2.20 \%$.

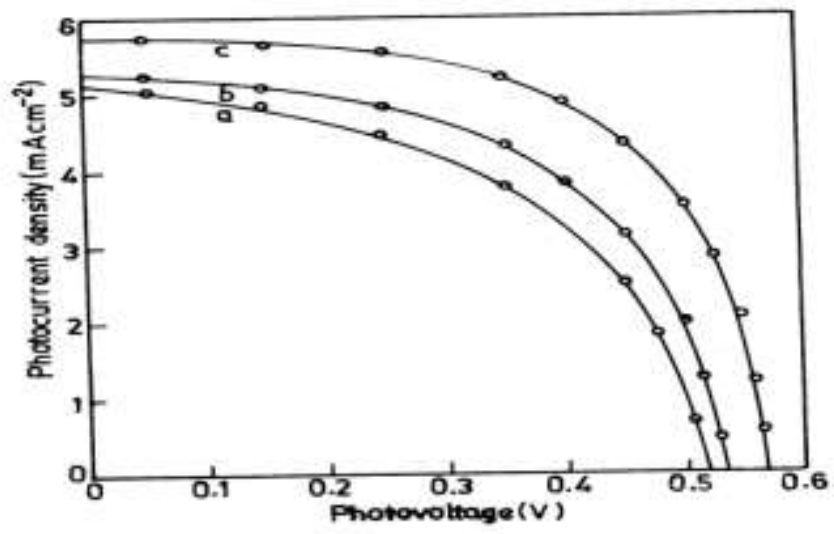

Fig. 3.5 - Photocurrent - photo voltage characteristics of ITO photo electrodes heat treated at different temperatures (a) $350^{\circ} \mathrm{C}$ (b) $400^{\circ} \mathrm{C}$ (c) $450^{\circ} \mathrm{C}$ 


\subsection{Table -Photovoltaic performance of ITO photo electrodes}

\begin{tabular}{|c|c|c|c|c|}
\hline $\begin{array}{c}\text { Température } \\
\left({ }^{\circ} \mathbf{C}\right)\end{array}$ & $\begin{array}{c}\mathbf{V}_{\text {oc }} \\
\text { (V) }\end{array}$ & $\begin{array}{c}\mathbf{J}_{\text {sc }} \\
(\mathbf{m A ~ c m}- \\
\mathbf{2})\end{array}$ & ff & $\begin{array}{c}\mathbf{n} \\
(\%)\end{array}$ \\
\hline 450 & 0.57 & 5.60 & 0.69 & 2.20 \\
\hline 400 & 0.53 & 5.30 & 0.65 & 1.82 \\
\hline 350 & 0.52 & 5.10 & 0.60 & 1.59 \\
\hline
\end{tabular}

\section{Conclusion}

ITO films with crystallite size in the range of $30-40 \mathrm{~nm}$ can be obtained. Films with Transmission in the range of $80-90 \%$ can be obtained. Resistivity in the range of $10^{-3} \mathrm{ohm} \mathrm{cm}$ to $10^{-4} \mathrm{ohm} \mathrm{cm}$ can be obtained. DSSC cells with ITO/dye/electrolyte/FTO configuration have yielded efficiencies in the range of $1.59 \%-2.20 \%$ can be fabricated.

\section{References}

[1] J. Chastain_Ed.., Handbook of X-ray Photoelectron Spectroscopy,(Perkin-Elmer, Minnesota, 1992.

[2] A.W.C. Lin, N.R. Armstrong, T. Kuwana, X-ray photoelectron/ Auger electron spectroscopy of tin and indium foils and oxides, Anal. Chem. 49 (9), (1977),1228-1235.

[3] E. Burstein, Anamalous optical absorption limit in AlSb, Phys. Rev. 93(3), (1952), 632 - 633

[4] N.Wan,T.Wang, H.Sun, G.Chen, L.Geng, X.Gan,S.Guo, J.Xu, L.Xu, KI.Chen, Indium tin oxide for silicon based electroluminescence devices prepared by electron beam devices, J.Non.cryst sol, 356 (18 - 19), (2010), 911 - 916.

[5] W.U. Huynh, J.J. Dittmer, A.P. Alivisatos, Hybrid nanorod polymer solar cells, Science, 295 (5564).(2002) 2425 - 2427. 